MSC 93A 30

\title{
Mathematical model for evacuation people from corridor-type buildings
}

\section{S. V. Malodushev, A. A. Rogov, R. V. Voronov}

Petrozavodsk State University, 33, Lenin pr., Petrozavodsk, 185910, Russian Federation

For citation: Malodushev S. V., Rogov A. A., Voronov R. V. Mathematical model for evacuation people from corridor-type buildings. Vestnik of Saint Petersburg University. Applied Mathematics. Computer Science. Control Processes, 2019, vol. 15, iss. 3, pp. 375-384.

https://doi.org/10.21638/11702/spbu10.2019.307

This article describes different techniques for calculating escape routes in cases of emergency. The article contains developed mathematical model that describes dynamic flows movement in a directed graph. Model parameters include undirected graph as a model of a building, initial flow values, flows sources and their sinks. The aim of our work was creating the model, an algorithm and software to illustrate human flows movement in cases of emergency. One of the major subtask of our work was illustration of such process in corridor-type buildings. We modelled a few real evacuation experiments performed in Petrozavodsk State University in different years. Results showed that suggested model is adequate and applicable for describing human flows movement in cases of emergency. Developed algorithm and software are applicable to work out escape routes and estimate duration of evacuation. Results obtained applicable for the following research of evacuation processes, building design and operation to achieve fire safety requirements.

Keywords: evacuation, dynamic flow, confluent flow, macroscopic model, corridor-type building.

Introduction. It is very important to minimize evacuation time and human sacrifices in the evacuation processes. Different approaches are used to investigate building evacuation. Existing mathematical models for building evacuation can be categorized as in [1] including mesocopic models in addition:

- Cellular Automata (CA) - evacuation area is represented as a grid and each occupant can take only one cell per unit time. The state of each cell depends on states of neighbour cells and the state of the considered cell. Examples of CA models were considered in $[2,3]$, the main of them are PedGo, EGRESS, SGEM and EVAC. CA models use one set of movement rules for each occupant, exact set of rules depends on specific CA model.

- Agent-based models - these models illustrates actions and interactions of autonomous agents. They consider individual parameters for each agent. Count of parameters depends on specific model (e. g. mobility group, walking speed, weight, projected area). Agent-based models are also known as microscopic models [4]. These models are implemented in such software applications as Simulex, Steps, BuildingExodus and Pathfinder, they also mentioned in [4].

- Flow-based models - these models do not consider personal behavior. All particles in such models have the same parameters. Only common characteristics are taking into account. These models are also known as macroscopic models [4]. Examples of macroscopic models were considered in [2], the main of them are Myriad, EgressComplexityModel

(C) Санкт-Петербургский государственный университет, 2019 
and VEgAS. Macroscopic models are similar to a black box due to internal procedures of their particles are unknown.

- Mesoscopic models - these type of models is a hybrid of microscopic and macroscopic models. Agents are split up into separate groups with common characteristics within the group (common exit, the same walking speed, etc.). Examples of mesoscopic models applied in evacuation tasks were considered in $[5,6]$.

In this research work we investigated macroscopic approach. The evacuation space in suggested model was presented as Dynamic Graph Network (DGN), where we illustrated evacuation processes. Quickest Flow Problem (QFP) is one of the major problem in DGN. Different researchers work out this problem [7-9]. QFP generalisation [7]: send given amount of flow from sources to sinks in the shortest possible time. We used DGN as a model of a corridor-type building to investigate QFP. Developed algorithm and software were used to model the evacuation processes.

Proposed model. The model of a building is a connected graph $G=(V, E)$, where $V$ is a set of vertices, $E$ is a set of edges, $E \subset\{\{u, v\} \mid u, v \in V\}$. Each vertex $v \in V$ has non-negative weight $w_{v 0}$ that means a number of particles in the vertex. For the corridortype buildings the value $w_{v 0}$ can be calculated with location algorithm considered at [10]. Evacuation process will be described as a flow on the graph. The flow determines a number of particles moving through edges from vertices $v \in V$ to vertices $u \in U, U \subseteq V$ (exits from a building).

Edges with positive flow value generate forest of rooted trees with roots from the set $U$. All paths in this forest are directed to the roots. Considered flow cannot be split. Such type of flows is known as confluent [9]. In case of splitting flows existing approaches can be used for QFP [7, 8, 11].

Lets call subgraph $H=(V, A)$ of the graph $G$ as covering rooted forest ( $A$ is a set of edges), if it meets the terms:

- subgraph $H$ is directed - movement direction is defined by exits (roots);

- out-degree $d^{-}(u)=0, \forall u \in U$ in subgraph $H$;

- out-degree $d^{-}(v)=1, \forall v \in V \backslash U$ in subgraph $H$;

- $\forall v \in V \backslash U$ has a path to a root $u \in U$.

Vertices $u \in U$ are roots of trees from the forest $H$. All vertices $v \in V$ are contained in the forest $H$ trees; $\Omega$ is a set of subgraphs $H ; \Gamma^{+}(v)$ is a set of vertices that are connected to vertex $v$ in the subgraph $H$ :

$$
\Gamma^{+}(v)=\{u \in V \mid(u, v) \in A\}, \quad v \in V
$$

$a(v)$ is a vertex to which an edge is directed from vertex $v \in V \backslash U$ in the subgraph $H$; $Q_{u v}$ is flow capacity for any edge $(u, v) \in E ; Q_{u v}=Q_{v u}, \forall u, v \in E$. $W_{v}$ is constraint for a number of particles in a vertex $v$ (vertex capacity); $w_{v t}$ is a number of particles in a vertex $v$ at unit time $t ; T$ is constraint for evacuation time; $Z \geqslant 0$ is a set of non-negative integers.

Definition. Flow is a function $x: A \times t \rightarrow Z_{\geqslant 0}$ that determines non-negative integer for each edge per unit time. This function has the following properties:

1) flow capacity constraint:

$$
0 \leqslant x_{u v} \leqslant Q_{u v} \quad \forall u, v \in A
$$

2) constraint for a number of particles in vertices:

$$
w_{v t} \leqslant W_{v} \quad \forall v \in V, \quad t=1, \ldots, T
$$


3) balance equations:

$$
\begin{gathered}
w_{v t}=w_{v, t-1}-x_{v a(v) t}+\sum_{u \in \Gamma(v)} x_{u v, t-1} \quad \forall v \in V \backslash U, t=1, \ldots, T, \\
w_{v t}=w_{v, t-1}+\sum_{u \in \Gamma(v)} x_{u v, t-1} \quad \forall v \in U, \quad t=1, \ldots, T ;
\end{gathered}
$$

4) particles count:

$$
\sum_{u \in U} w_{u T}=\sum_{v \in V \backslash U} w_{v 0}
$$

In formulas (1)-(5) $x_{u v}$ is the value of function $x$ for pair $(u, v)$. The main task is to find such rooted forest $H$ that allows to get quickest flow for each vertex $v \in V \backslash U$ with positive value of $w_{v 0}$ (this is a criterion of optimality for considered model). Objective function can be described as

$$
x \rightarrow \min \sum_{v, a(v)} t_{v, a(v)} x_{v, a(v)} \quad \forall v \in V,
$$

where $t_{v, a(v)}$ is transition time for edge $(v, a(v))$.

Quickest flow problem could be considered similar to a problem of maximal dynamic flow that was described in [12], but sources in the evacuation process have limited value of particles $w_{v 0}$. As a result flow value from a non-empty vertex can be less than capacity of its exiting edge. In this case QFP can be formulated in [8] as

$$
T \geqslant \frac{|\hat{x}|+\sum_{v, a(v)} t_{v, a(v)} x_{v, a(v)}}{|x|} \quad \forall v \in V,
$$

where $|\hat{x}|$ is a flow value that should be transferred from a source to a sink; $|x|$ is the total amount of flow that leaves the source. Evacuation process requires to move all occupants from sources to sinks that is described by equation (5). As a result $|\hat{x}|=|x|$ in equation (7) and we use the objective function (6).

We consider a building as non-overlapping sets of zones. Each zone is a room or a part of corridor, where occupants can concentrate. Vertices in the model are the equivalent of zones. A couple of vertices is adjacent if related zones are nearest-neighbours. Occupants can move only between such zones and as a result flow is progressing between adjacent vertices only. Similar approach is used in [8]. Each edge can be split to small zones (vertices), where a flow is progressing through them in sequence. Such approach allows to move particles between a couple of vertices per unit time fulfilling by that the third property of the model.

Proposed algorithm. For testing purposes we developed a heuristic algorithm that includes the following stages:

1. Get undirected graph $G$ with all required properties (vertices with particles, number of particles, capacity of vertices, length and width for each edge). At this stage, the algorithm also gets available flow parameters including mobility groups $\left(M_{i}\right.$, where $i$ is a group number) and their proportion, flow density constraint $\left(D_{\max }, \mathrm{m}^{2} / \mathrm{m}^{2}\right)$, evacuation time constraint $(T)$, max count of paths from one non-empty vertex $\left(\max d^{-}(v)\right)$.

2. Set weights for all edges. Edge weight is determined as transferring time of one particle for selected values of $M_{i}$ and flow density value $D_{i}=0.1, \mathrm{~m}^{2} / \mathrm{m}^{2}$. Flow velocity 
is determined as function $V\left(M_{i}, D_{i}\right)$, its values are described in GOST 12.1.004-91 (name is in English) and SP 59.13330.2012 (name is in English). Transferring time for one particle is calculated as

$$
t_{u v}^{1}=l_{u v} / V\left(M_{i}, D_{i}\right)
$$

where $l_{u v}$ is the edge $\{u, v\}$ length.

3. Search for escape routes for non-empty vertices by using Dijkstra's algorithm. A separate escape route is considered as a simple chain. Weight of each chain is calculated as a sum of their edges weights that are recalculated as

$$
c_{\{v, a(v)\}}=\frac{d^{+}(v) \cdot d^{+}(a(v)) \cdot d^{-}(v) \cdot d^{-}(a(v))}{\min \left(W_{\{v, a(v)\}}, W_{v}, W_{a(v)}\right)},
$$

here $W_{\{v, a(v)\}}$ is the edge $\{v, a(v)\}$ capacity. Chain priority depends on its weight - the lower weight value provides the higher priority.

4. Choose the covering rooted forest $H$ and move all flows to its roots. At this stage, simple chains will be selected for each non-empty vertex. Figures 1 and 2 illustrate a process of such selection. Figure 1 contains an example of simple chains selected for each non-empty vertices (steps 1-7):
1. $J:\{J, H, F, C, A, B\}$.
5. $D:\{D, C, A, B\}$.
2. $H:\{H, F, C, A, B\}$.
6. $L:\{L, K, N, O\}$.
3. $G:\{G, F, K, N, O\}$.
7. $M:\{M, K, N, O\}$.
4. $E:\{E, C, A, B\}$.
8. $G:\{G, F, K, N, O\} \rightarrow\{G, F, C, A, B\}$.

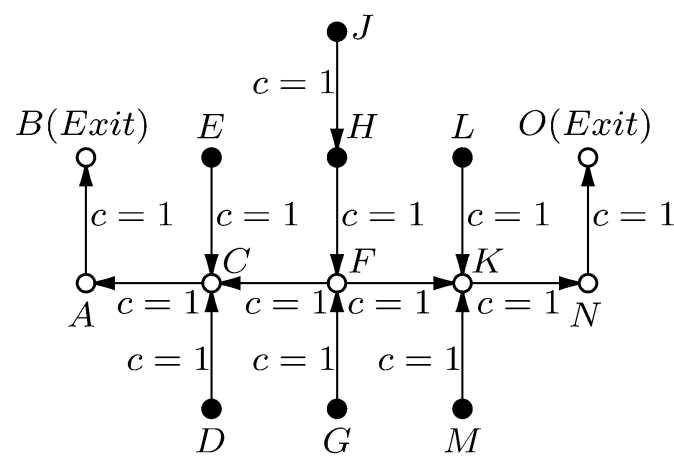

Figure 1. Directed graph $(\Omega)$

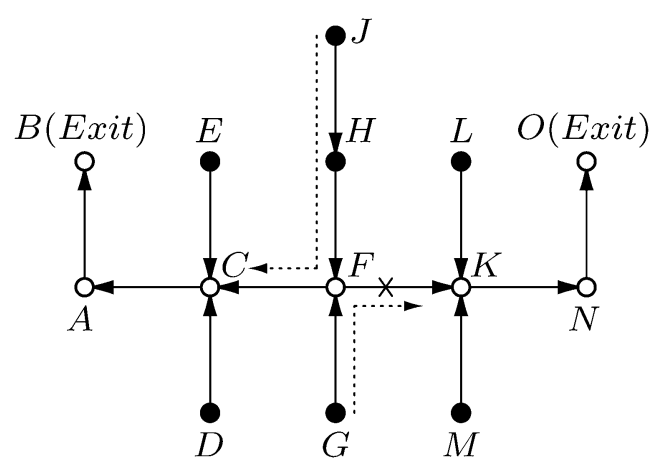

Figure 2. Rooted forest $(H)$

A set of selected chains can be illustrated as a directed graph that includes all possible sub-graphs $H$ (edges directions can differ in different subgraphs, that is $\Omega$ ). In the next step the algorithm validates out-degrees for all vertices going through selected chains from the shortest one to the longest one. If any vertex has $d^{-}(v)>1$ the algorithm excludes the appropriate chain from the graph (step 8, figure 2). Covering rooted forest $H$ will be gotten before flow movement. After that all flows will be sent in accordance with the model properties.

Figures 3 and 4 describe implemented flow movement into common exit and trough an occupied area (vertex) appropriately. Exits don't have constraints for their capacity as a result $W_{u} \rightarrow \infty, \forall u \in U$. Nevertheless exits bandwidth is limited by their door way sizes. Figure 3 describes movement for two flows into a common exit based on assumption 
that both flows are using the same door (exit has only one door). In the algorithm we are considering flows as groups of particles that can be placed on a segment $b$ equal to edge width. Only one group can be moved into $u \in U$ per unit time, this process can be described as

$t_{i}$ : both flows are ready to be moved into vertex $u$;

$t_{i+1}$ : group $x_{e_{1}}^{b}$ (5 particles) moves into vertex $u$;

$t_{i+2}$ : group $x_{e_{2}}^{b}$ (3 particles) moves into vertex $u$;

$t_{i+3}$ : group $x_{e_{1}}^{b}$ (5 particles) moves into vertex $u$;

$t_{i+4}$ : etc.

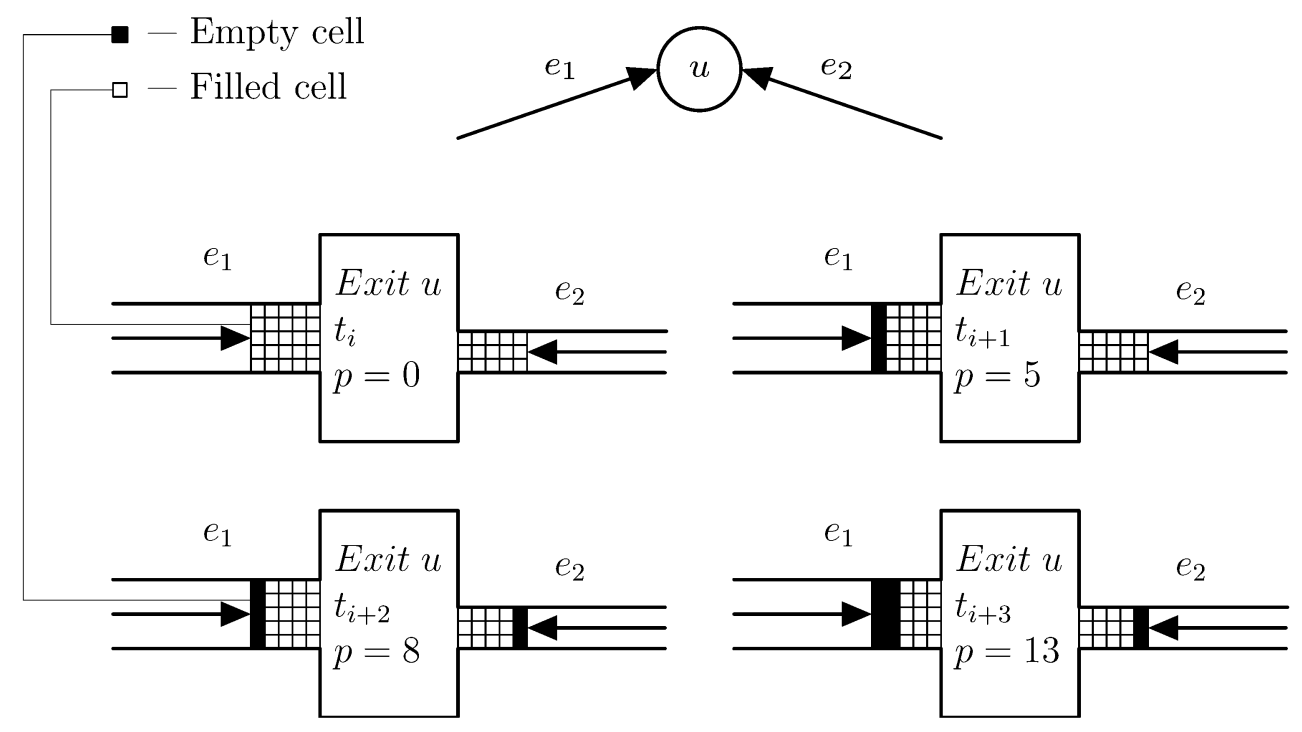

Figure 3. Flows movement into a common exit

For the occupied area detailed example is on the figure 4. Groups sizes can differ for both inbound and outbound edges. This example illustrates a case, where outbound edge width is less than the inbound one:

$t_{i}$ : a number of particles is equal to the vertex capacity $\left(w_{v t_{i}}=W_{v}\right)$, the flow is not moving at this instant of time;

$t_{i+1}$ : group $x_{e_{2}}^{b}$ (3 particles) left the vertex and the same number of particles $\left(x_{e_{1}}^{b}>\right.$ $x_{e_{2}}^{b}, x_{e_{1}}^{b}$ should be decreased) arrived there at the same instant of time;

$t_{i+2}$ : group $x_{e_{2}}^{b}$ (3 particles) left the vertex and the same number of particles arrived there at the same instant of time;

$t_{i+3}$ : etc.

Described model cannot be considered as a microscopic model or a mesoscopic one. In the algorithm we implemented different mobility groups described in http://docs.cntd.ru/document/1200089976SP 59.13330.2012 to get a tradeoff between microscopic and macroscopic approaches. As a result the algorithm allows to send multicommodity flows. Mobility group cannot be assigned to a separate particle or a group of particles. The algorithm recalculates flows velocity by using the following equation:

$$
\widetilde{V}_{u v}=\frac{\sum_{j=1}^{m} \widetilde{V}_{u v}^{j} p^{j}}{\sum_{j=1}^{m} p^{j}},
$$


where $\widetilde{V}_{u v}^{j}$ is flow velocity $(\mathrm{m} / \mathrm{min})$ for mobility group $j$ on the edge $\{u, v\} \in E ; p^{j}$ is number of particles from mobility group $j ; m$ is number of mobility groups. $\widetilde{V}_{u v}^{j}$ depends on edge type and flow density for mobility group $j$ on the edge $\{u, v\} \in E$ denoted as $\widetilde{D}_{u v}^{j}$ (can be calculated similar to equation (8)).

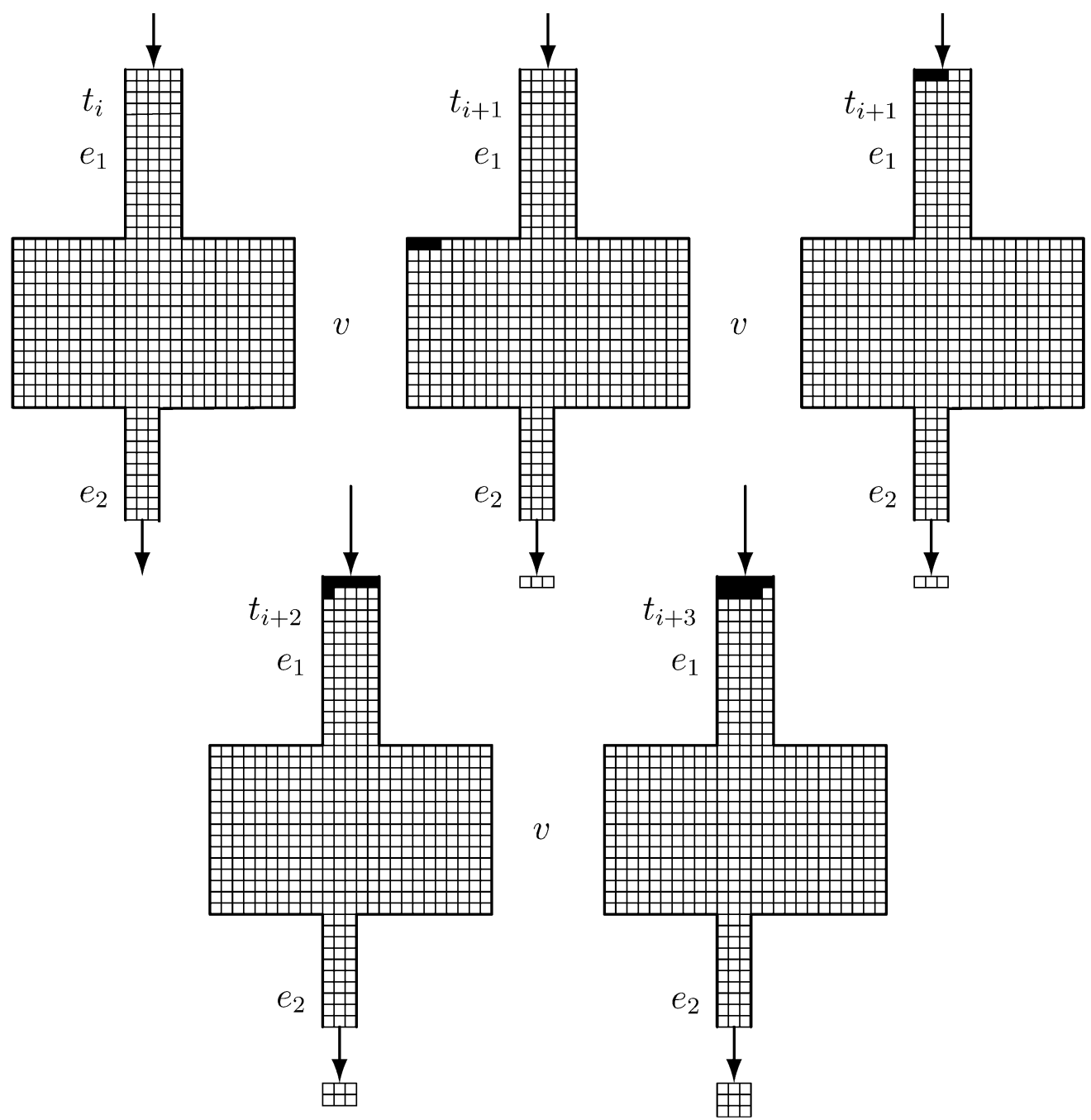

Figure 4. Flow movement trough an occupied area (vertex)

Experiments. All experiments were done in the Petrozavodsk State University. Actual and calculated evacuation time are presented in the Table. There were 8 emergency training exercises in the main building that were performed in different years. We didn't have information about occupants positions in the real experiments. In the modelled experiments occupants were placed in classrooms on a pro rata basis (in accordance with count of chairs). Based on information provided we used the following proportion in all modelled experiments: $95 \%$ of occupants from mobility group $M_{1}$ and $5 \%$ of occupants from mobility group $M_{2}$. 
Table. Results for real and modelled experiments

\begin{tabular}{|c|c|c|c|c|}
\hline Experiment & $\begin{array}{c}\text { Count of } \\
\text { occupants }\end{array}$ & $\begin{array}{c}\text { Actual evacuation } \\
\text { time, sec }\end{array}$ & $\begin{array}{c}\text { Calculated evacuation } \\
\text { time, sec }\end{array}$ & $\begin{array}{c}\text { Difference, } \\
\%\end{array}$ \\
\hline 1 & 833 & 295 & 246 & 16.61 \\
\hline 2 & 663 & 600 & 227 & 62.17 \\
\hline 3 & 715 & 330 & 233 & 29.39 \\
\hline 4 & 630 & 320 & 224 & 30.00 \\
\hline 5 & 805 & 360 & 219 & 34.17 \\
\hline 6 & 563 & 300 & 212 & 27.00 \\
\hline 7 & 397 & 300 & 237 & 29.33 \\
\hline 8 & 807 & 280 & & 15.36 \\
\hline
\end{tabular}

Actual and calculated average values of evacuation time for the results are 5.80 and 3.82 minutes accordingly. In all cases calculated evacuation time is less than the actual one. The reason of that can be explained by occupants knowledge about available exits. If people don't know the structure of the building well enough, they will use an exit that was used as an entrance. Such scenario excludes other exits that can be easier to reach [1]. Also people can prefer blocked exits, in such cases they have to spend time for searching another evacuation path. And one more additional factor that increases the actual evacuation time is an emergency training exercise. In case of a real emergency situation occupants will leave the building faster, but it also depends on count of blocked exits.

Figure 5 contains detailed results for the 8th experiment. We modelled evacuation process from all floors (considered building consist of 5 floors). Source of combustion was at the same place on the $2 \mathrm{~d}$ floor for both real and modelled experiments. Exits 3 and 4 were technically blocked, they are placed in a recital room that was closed in all experiments.

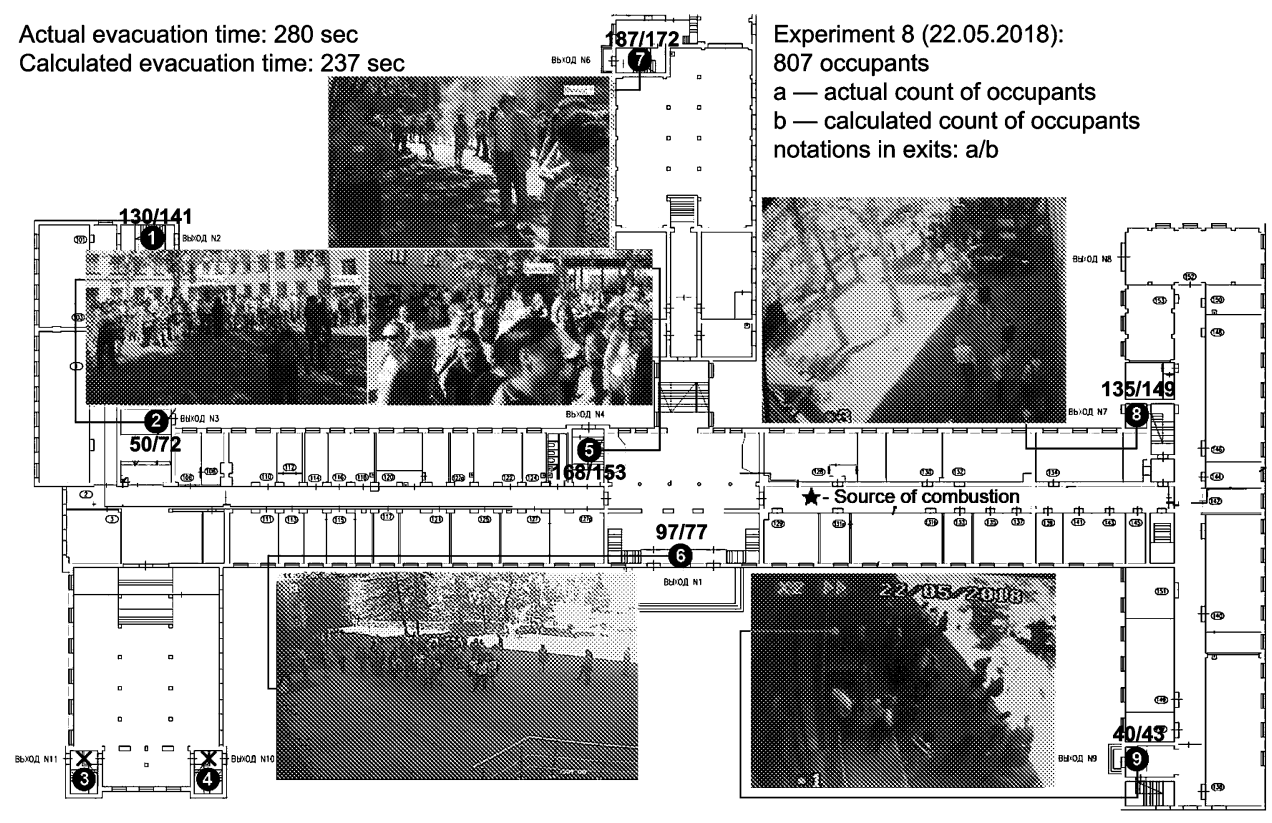

Figure 5. Evacuation time for used exits

For the estimation purposes we have coined a term real capacity of an exit (RCE) that means count of occupants moving through an exit per unit time in the evacuation 
process limited by $T$ value. RCE value can be calculated as

$$
\mathrm{RCE}^{u}=\frac{\sum_{i=1}^{n} p_{i}^{u}}{\hat{T}^{u}}, u \in U,
$$

where $u$ is an exit number, $p_{i}^{u}$ is a particle with index $i$ in the exit $u, \hat{T}^{u}$ is evacuation time (sec) for the exit $u$. Figure 6 contains RCE curves for both real and modelled experiments for all used exits.

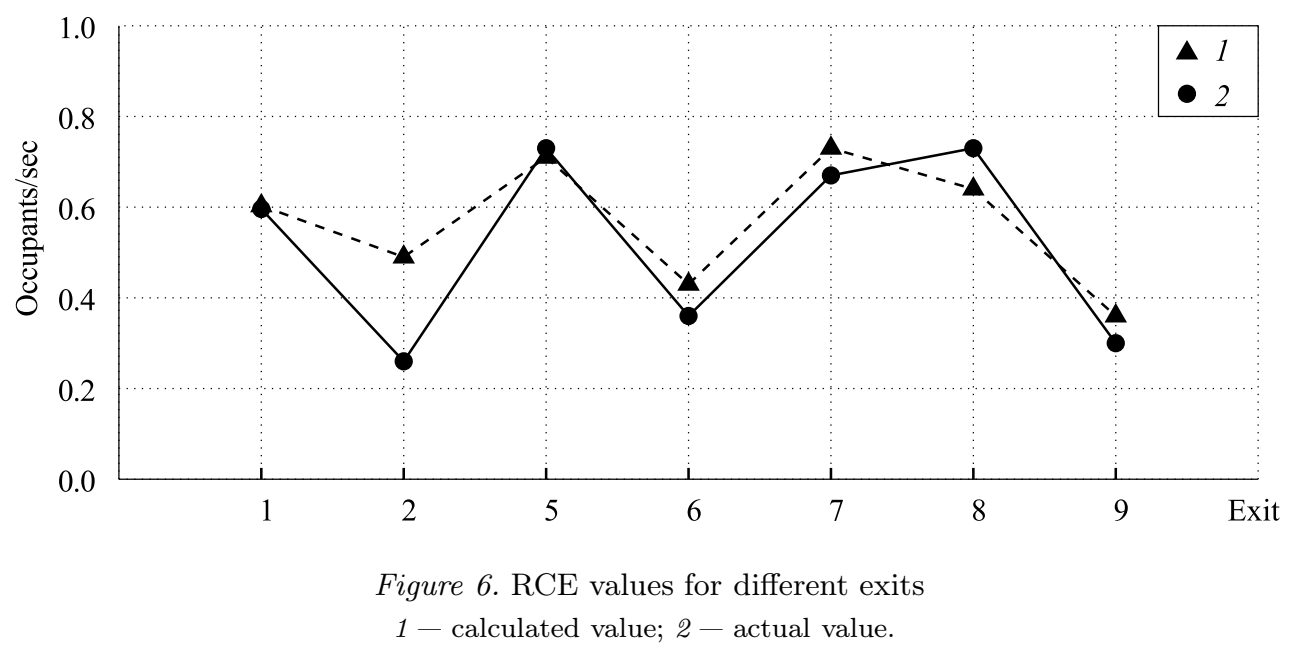

Both curves have similar RCE values for all exits except the $2 \mathrm{~d}$ one. Actual RCE value for the $2 \mathrm{~d}$ exit is substantially smaller (0.26 vs. 0.49$)$. Actual result for the $2 \mathrm{~d}$ exit can be explained by a small amount of occupants for a large value of $\hat{T}$ (195 vs. 148). Correlation coefficient for RCE curves is 0.905 , this result confirms adequacy of the algorithm and the model properties.

Conclusion. The obtained results allow to conclude that developed model, the algorithm and software can be used to emulate evacuation processes in the corridor-type buildings. The model describes dynamic flows movement trough a directed graph, the algorithm used this model to move the flows, and developed software implements the algorithm for modelling evacuation process. Also, the software can be used in the design stage of buildings to meet the fire safety regulations.

At present, our model does not take into account flows separation in vertices and structural dynamic changes that could occur after starting evacuation process, for instance, new sources of combustion that block some evacuation paths.

We believe that our model and the algorithm can be a good start point for the further researches of evacuation processes in different types of buildings. Model limitations mentioned above also will be covered in the further researchers.

\section{References}

1. Almedia J. E., Rosetti R., Coelho A. L. Crowd simulation modeling applied to emergency and evacuation simulations using multi-agent systems. arXiv:1303.4692. 2013.

Available at: https://arxiv.org/abs/1303.4692 (accessed: 20.11.2018).

2. Kuligowski E. D., Peacock R. D. A review of building evacuation models - 100. Bureau Dr. Gaithersburg, MD 20899, USA, National Institute of Standards and Technology Publ., 2005, Technical Note 1680. 
3. Tissera P. C., Printista M., Errecalde M. L. Evacuation simulations using cellular automata. JCS\& T, 2007, vol. 7, no. 1, pp. 14-20.

4. Hamacher H. W., Tjandra S. A. Mathematical modeling of evacuation problems: A state of the art. Pedestrian and Evacuation Dynamics, 2002, no. 24, pp. 227-266.

5. Lao A., Tekomono K. Multi exit configuration of mesoscopic pedestrian simulation. arXiv: 1609.01475. 2016. Available at: https://arxiv.org/abs/1609.01475 (accessed: 22.11.2018).

6. Shi M., Wai Ming Lee E., Ma Y. A newly developed mesoscopic model on simulating pedestrian flow. Procedia Engineering, 2018, vol. 211, pp. 614-620.

7. Fleischer L., Skutella M. Quickest flows over time. Society for Industrial and Applied Mathematics, 2007, vol. 36, no. 6, pp. 1600-1630.

8. Lin M., Jaillet P. On the quickest flow problem in dynamic networks - A parametric min-cost flow approach. Proceedings of the Twenty-Sixth Annual ACM-SIAM Symposium on Discrete Algorithms. San Diego, CA, USA, 2015, pp. 1343-1356.

9. Arumugam G. P., Augustine J., Golin J. G. et al. Optimal evacuation flows on dynamic paths with general edge capacities. arXiv:1606.07208v1 [cs.DS]. 2016. Available at: https://arxiv.org/abs/1606.07208 (accessed: 02.03.2017).

10. Malodushev S. V., Rogov A. A. Determination of locations in corporate Wi-Fi networks. Series Mathematical Modelling, Programming \& Computer Software, Bulletin of the South Ural State University. 2016, vol. 9, no. 1, pp. 92-104.

11. Voronov R. V. The fault-tolerant metric dimension of the king's graph. Vestnik of Saint Petersburg University. Applied Mathematics. Computer Science. Control Processes, 2017, vol. 13, iss. 3, pp. 241-249.

12. Ford L. R., Fulkerson D. R. Constructing maximal dynamic flows from static flows. Operations Research, 1958, vol. 6, no. 3, pp. 419-433.

Received: April 19, 2019.

Accepted: June 06, 2019.

Author's information:

Sergei V. Malodushev — PhD Sci. in Engineering; svm@petrsu.ru

Aleksandr A. Rogov - Dr. Sci. in Engineering, Professor; rogov@petrs.ru

Roman V. Voronov - Dr. Sci. in Engineering, Associate Professor; rvoronov76@gmail.com

\title{
Математическая модель для эвакуации людей из зданий коридорного типа
}

\author{
С. В. Малодушев, А. А. Рогов, Р. В. Воронов
}

Петрозаводский государственный университет, Российская Федерация, 185910, Петрозаводск, пр. Ленина, 33

Для цитирования: Malodushev S. V., Rogov A. A., Voronov R. V. Mathematical model for evacuation people from corridor-type buildings // Вестник Санкт-Петербургского университета. Прикладная математика. Информатика. Процессы управления. 2019. Т. 15. Вып. 3. C. 375-384. https://doi.org/10.21638/11702/spbu10.2019.307 (In English)

Рассматриваются различные подходы для вычисления маршрутов эвакуации в экстренных ситуациях. Разработана математическая модель, описывающая перемещение динамических потоков в ориентированном графе. В перечень параметров модели входят неориентированный граф в качестве модели здания, исходная величина потока, его источники потока и стоки. Цель данной работы заключалась в создании модели, алгоритма и программного обеспечения для демонстрации движения потоков людей в экстренных ситуациях. Смоделированы несколько реальных экспериментов по эвакуации, проведенных в здании Петрозаводского государственного университета в различные годы. Подтверждена адекватность предложенной модели и установлена ее применимость для 
описания движения потоков людей в экстренных ситуациях. Полученные результаты можно использовать для дальнейшего исследования процессов эвакуации, проектирования и эксплуатации зданий с целью соблюдения требований пожарной безопасности. Ключевые слова: эвакуация, динамический поток, неразделимый поток, макроскопическая модель, здание коридорного типа.

Контактная информация:

Малодушев Сергей Викторович - канд. техн. наук; svm@petrsu.ru

Рогов Александр Александрович - д-р техн. наук, проф.; rogov@psu.karelia.ru

Воронов Роман Владимирович - д-р техн. наук, доц.; rvoronov76@gmail.com 